\title{
Pelatihan Pemahaman Multikulturalisme pada Komunitas Nahdlatul Ulama di Desa Tamantirta, Kasihan, Bantul
}

\author{
Arif Akhyat \\ Departemen Sejarah, Fakultas Ilmu Budaya, Universitas Gadjah Mada \\ Korespondensi: arief.fib@ugm.ac.id
}

\begin{abstract}
Multiculturalism is a new concept in social science that is used to be the main discussion in community service activities at Jam'iyyah and Jama'ah Nahdlatul Ulama (NU) in Tamantirto Village, Kasihan, Bantul, Yogyakarta. Through the concept of multiculturalism, Jama'ah and Jam'iyyah NU began to try to understand the teachings of NU which have the same principles as Tasawasuth, Tasamuh, Tawazun and I'tidal. With a mixture of online (Whatapps Group and WA Japri) and offline (direct FGD) methods, this service has provided the concept of multiculturalism as a training subject to Jama'ah and Jam'iyyah of NU. The results achieved in this service, opened an understanding of tolerance, the concept of Islamic brotherhood (Ukhuwwah Islamiyah) and a pluralistic social awareness. The emergence of this awareness of multiculturalism, although among $N U$ circles, often referred to the concepts of Tawasuth, Tasamuh, Tawazun and I'tidal, Jama'ah began to expand the way of life in society amidst differences and complex social networks.
\end{abstract}

Keywords: multiculturalism; Nahdlatul Ulama

\begin{abstract}
Abstrak
Multikulturalisme sebagai konsep baru dalam ilmu sosial menjadi pembahasan pokok dalam kegiatan pengabdian pada Jam'iyyah maupun Jama'ah Nahdlatul Ulama (NU) di Desa Tamantirto, Kasihan, Bantul, Yogyakarta. Melalui konsep multikulturalisme, Jama'ah maupun Jam'iyyah NU mulai mencoba memahami dan mengaitkan dengan ajaran NU yang memiliki kesamaan prinsip dengan Tasawasuth, Tasamuh, Tawazun dan I'tidal. Dengan metode campuran daring (Whatapps Group dan WA Japri) dan luring (FGD langsung), pengabdian ini telah memberikan pengenalan konsep multikulturalisme kepada Jama'ah dan Jam'iyyah NU sebagai praktik sosial-keagamaan. Hasil yang dicapai pada pengabdian ini adalah terbukanya pemahaman tentang toleransi, konsep persaudaraan Islamiyah (Ukhuuwah Islamiyah) dan kesadaran bermasyarakat yang majemuk. Munculnya kesadaran multikulturalisme ini, walaupun di kalangan NU, sering merujuk pada konsep Tawasuth, Tasamuh, Tawazun dan I'tidal, tetapi Jama'ah mulai semakin luas cara hidup bermasyarakatnya di tengah-tengah perbedaan dan jaringan sosial yang rumit.
\end{abstract}

Kata Kunci: multikulturalisme; Nahdlatul Ulama 


\section{Pendahuluan}

Multikulturalisme merupakan sebuah sudut pandang kajian sosial budaya yang menyatakan bahwa struktur sosial yang bertingkat dan beragam itu memiliki ikatan satu sama lain dan dibangun atas rasa saling menghargai. Oleh karena itu, dalam rangka untuk memenuhi kebutuhan akan pengetahuan tentang keragaman, saling keterkaitan dan saling memahami dalam masyarakat yang majemuk, terutama yang terkait dengan proses adaptasi; relasi-relasi sosial-budaya; politik; dan ekonomi, perlu ada metode bagaimana muktikulturalisme itu dipahami dan dipraktikkan dalam kehidupan sehari-hari (Dhont et al., 2009; Abdullah, 2005). Deskripsi tentang proses-proses hegemoni sosial, politik, budaya, dan ekonomi serta bagaimana kekuatan eksternal tersebut membentuk sikapsikap yang intoleran, egois, dan individualis sangat dibutuhkan sebagai pemahaman terhadap budaya dan perilaku sosial yang mengganggu keteraturan sosial (Lombard, 1996). Pengetahuan tentang sistem yang toleran dan saling menghargai menjadi syarat bagaimana hubungan sosial itu dibangun agar dapat menghindari konflik dan aktivitas kontraproduktif. Multikulturalisme juga dapat digunakan untuk menjelaskan proses pembentukan identitas, subkultur, kelompok sosial serta akibat yang ditimbulkannnya, baik bersifat internal maupun eksternal (Klein, 1993).

Secara spesifik, kegiatan ini menjadi cara untuk menjelaskan kepada peserta pengabdian agar memahami sebuah kelompok sosial lain dengan memperhatikan latar belakang sosial, proses dan pola aktivitas sosial, serta pola pengelompokan secara sosial sehingga dinamika sosial yang berkembang dapat dipahami (van Leur, 1955). Perkembangan keragaman tingkatan sosial yang dipengaruhi oleh proses politik, ekonomi, serta sosial budaya menjadi hal yang sangat penting untuk dipahami sebagai cara memahamkan bahwa multikulturalisme adalah persoalan penting dan historis yang perlu dijelaskan (Roelofsz, 1969). Dengan demikian, pada tahapan yang paling sederhana dan paling terbatas, kegiatan ini akan memberikan pendampingan bagaimana multikuluralisme sebagai realitas sosial menjadi rujukan berperilaku, baik sosial, ekonomi, politik, dan bahkan keagamaan.

Secara spesifik, kegiatan ini menjadi cara untuk menjelaskan kepada peserta pengabdian agar memahami sebuah kelompok sosial lain sehingga dinamika sosial yang berkembang dapat dipahami (van Leur, 1955). Dengan demikian, pada tahapan yang paling sederhana dan paling terbatas, kegiatan ini akan memberikan pendampingan bagaimana multikuluralisme sebagai realitas sosial menjadi rujukan berperilaku, baik sosial, ekonomi, politik, dan bahkan keagamaan.

\section{Pendekatan Pelaksanaan Program}

Proses pengabdian ini dilakukan melalui beberapa tahap. Tahap awal ialah menjaring pemahaman secara individual melalui teknik dialog, baik melalui Whatapps Group (WAG) dan WhatsApps Jaringan Pribadi (WA Japri) dengan anggota Syuriah (legislatif), Tanfidziyah (eksekutif), maupun Jama'ah. Ketiga kelompok Jama'ah tersebut digali pandangan dan tafsirnya terhadap ajaran Abl al Sunnah wa Al Jama'ah dengan prinsip Tawasuth (moderat), Tawazun (keseimbangan), Tasamuh (toleran), dan I'tidal (keadilan) melalui analisis konten komen WA dan dalam beberapa kali dilakukan pertemuan 
dengan protokol kesehatan, baik pertemuan resmi maupun dilakukan bersama kegiatan olah raga.

Metode pertemuan secara total masih tidak memungkinan, tetapi sering pula diselipkan pada acara-acara rapat pengurus yang dihadiri pengurus Syuriah dan Tanfidziyah. Pada acara pengurus tersebut sering diselingi dengan mendengarkan pandangan-pandangan Jama'ah terkait dengan isu-isu sosial di sekitar desa. Menurut Jama'ah, isu desa mulai dari yang paling sensitif adalah ajaran agama yang dianggap menyimpang, isu Khilafah, isu ibadah terkait fungsi dan praktik keagamaan di masjid, hingga isu-isu bacaan ayat Al-Qur'an yang dianggap kurang baik untuk sebagai bacaan saat salat.

Di samping isu-isu keagamaan yang sifatnya wajib, dibicarakan pula pentingnya acara tahlilan, sholawatan, dan doa bersama - sering disebut istighosah. Secara konseptual, Jama'ah NU di Tamantirto tidak pernah melakukan klaim-klaim kebenaran atas kelompok lain. Hasil dari diskusi melalui WAG, WA Japri, dan pertemuan saat rapat pengurus dijadikan sebagai dasar untuk memetakan tingkat pemahaman Jama'ah NU terhadap konsep multikulturalisme. Hasil pemetaan informasi dan tingkat pemahaman multikulturalisme itu kemudian dikomparasikan dengan konsep-konsep yang ada dalam ajaran NU, ahl al Sunnah wa al Jama'ah wa al Nahdliyyah dengan mengacu pada konsep Tawazun, Tasamuh, Tawasuth dan I'tidal dalam NU. Hasil dari analisis itu digunakan untuk memberikan materi pelatihan terkait dengan multikulturalisme, yakni memberikan penambahan unsur-unsur sosial yang relevan dengan praktik-praktik keagamaan. Melalui metode diskusi dan ceramah secara sederhana, pengabdian ini kemudian diakhiri dengan perumusan dan analisis tingkat pemahaman terkait dengan multikultralisme di kalangan Nahdliyyin.

\section{Pelaksanaan Program}

\section{NU dalam Konteks Desa}

Desa Tamantirto terletak di Kecamatan Kasihan, Kabupaten Bantul, Yogyakarta. Desa ini memiliki posisi yang strategis karena terdapat beberapa kampus dan perusahaan. Desa ini memiliki 10 pedukuhan, yaitu Geblagan, Gatak, Ngebel, Ngrame, Jetis, Jadan, Brajan, Gonjen, Kasihan, dan Kembaran. Setiap pedukuhan memiliki beberapa ciri khusus, terutama dalam hal orientasi keagamaannya. Dukuh Kasihan, Brajan, dan kampung Tlogo memiliki penduduk yang banyak berorientasi Nahdlatul Ulama daripada dukuh yang lain. Jumlah penduduk pada semester dua tahun 2019 tercatat berjumlah 8.363 laki-laki dan 8.533 perempuan. Jumlah penduduk secara keseluruhan adalah 16.896 (Tamantirto.bantulkab.go.id, 2020).

Desa Tamantirta merupakan desa yang termasuk padat penduduknya karena didukung oleh fasilitas transportasi, fasilitas ekonomi, lembaga pendidikan, dan kesehatan yang memadai. Oleh karena itu, secara sosial, desa ini berpotensi berkembang dengan berbagai kemungkinan berdasar kecenderungan perubahan sosial ekonomi desa. Orientasi pendidikan tinggi lebih didominasi oleh Universitas Muhammadiyah Yogyakarta, Universitas Alma Ata, Stikes Jenderal Ahmad Yani, dan Universitas Aisyiyah Yogyakarta. Selain itu, terdapat pula sejumlah 15 lembaga di tingkat PAUD dan 11 lembaga di tingkat sekolah dasar, baik negeri maupun swasta. Di Desa Tamantirto 
terdapat 1 lenmbaga di tingkat sekolah menengah pertama dan tidak ada sekolah menengah atas (Tamantirto, bantulkab.go.id., 2020).

Tingginya percepatan penduduk akibat pendidikan semakin membuat desa ini mengalami modernisasi. Berbagai warung, kafe, dan beberapa warung modern sebagaimana swalayan muncul. Dari segi orientasi keagamaan berdasarkan sebaran masjid dan aktivitas keagamaan, desa ini didominasi oleh kelompok sosial yang berorientasi keagamaan Muhammadiyah. Dari sejumlah masjid, hanya 1 masjid di Brajan yang dipastikan berorientasi Nahdlatul Ulama (NU). Jumlah Jama'ah Nahdliyyin juga tidak sebanding dengan jumlah warga Muhammadiyah. Data statistik belum ditemukan sampai pengabdian ini dilakukan (interview dengan Najid, 2020).

Minimnya komunitas NU memberikan pancingan untuk tetap muncul dengan berbagai kegiatan sosial, baik kegiatan pengajian kitab, selawatan, pengajian akbar, kelompok-kelompok zikir, dan beberapa kegiatan sosial sebagaimana bakti sosial, santunan anak yatim dan duafa, serta bantuan saat hari-hari besar Islam. Rutinitas kegiatan pengajian selama pandemi Covid-19 mulai terganggu, acara-acara yang mengharuskan berkumpul juga tidak bisa dilakukan secara penuh. Oleh karena itu, kegiatan yang masih berjalan lebih ke kegiatan bakti sosial dan santunan anak yatimduafa. Kegiatan rapat resmi masih dilakukan dengan pembatasan jarak serta protokol kesehatan. Pada praktiknya, kegiatan dan cara pandang Jama'ah Nahdliyyin dalam menyikapi persoalan sosial keagamaan dihadapkan pada hal-hal berikut ini.

- Perbedaan pemahaman tentang multikulturalisme (sebuah pemahaman sederhana tentang pengakuan perbedaan dan penghormatan kepada yang lain)

- Kelompok Nahdliyyin (Jama’ah NU), terutama di kalangan Nahdliyyin di Desa Tamantirta, merupakan kelompok sosial yang memiliki keragaman pemahaman tentang "perbedaan" dan penghormatan kepada yang lain.

- Perlu dilihat tingkat pemahaman terhadap isu multikulturalisme dengan mempertimbangkan pengalaman pendidikan terutama terkait ke-NU-an.

\section{Nabdlatul Ulama dan Persoalan Multikultralisme}

NU merupakan organisasi yang banyak pendukungnya dari kalangan pesantren (Haidar, 1998). Pesantren menjadi basis Jama'ah NU dan bahkan dalam praktik keagamaan, Jama'ah NU selalu merujuk pada pendapat kyai di pesantren. Pesantren dan NU seolah menjadi subkultur yang membesar dalam Islam tradisi dengan kekuatan misi kulturalnya (Wahid, 1989:193-204). NU kemudian menjadi kekuatan kultural yang mencoba mengombinasikan antara ajaran-ajaran Fiqhiyyah (struktur yuridis formal) dan aspek kulturalnya. Belum dan bahkan sulit menghitung jumlah warga NU di Desa Tamantirto. Data statistik dan Monograf Desa belum terisi, kecuali yang dianggap penting oleh desa, yakni pekerjaan.

Pendidikan, fasilitas desa, kemajuan ekonomi dan bahkan keagamaan tidak ada dan tampaknya tidak mudah mendata agama berdasarkan orientasi keagamaan warga. Kesulitan tersebut bisa diakibatkan oleh rumitnya menentukan orientasi keagamaan atau mungkin akibat ketidakjelasan orientasi keagamaan karena relasi sosial yang cair dan tidak ditentukan oleh orientasi keagamaan tertentu. Sebuah aktivitas keagamaan yang biasa berjalan, Jama'ah NU melakukan ibadah di masjid Muhammadiyah, sebagaimana di Dusun Brajan dan Tlogo. Begitu juga warga Muhammadiyah yang mengikuti tahlilan 
dan acara-acara pengajian NU. Bahkan, di Dusun Tlogo terdapat masjid yang pengurus (takmir) masjidnya diampu oleh orang berorientasi NU dan Muhammadiyah (FGD Pengurus NU, 2020).

Kehidupan sosial keagamaan dengan tidak memandang orientasi keagamaan menjadi penting untuk melihat lebih jauh pembelahan ke-NU-an, kemuhammadiyahan, dan lembaga keagamaan lain sebagai entitas multikulturalisme pada tingkat yang paling dasar. Hal itu juga menjadi awal untuk melihat bagaimana relasi-relasi keagamaan pada tingkat akar rumput berjalan. NU dan Muhammadiyah, tentu lebih dari itu sebagaimana kelompok-kelompok Salafi, tampak mulai menjadi perhatian di Desa Tamantirto. Kelompok Salafi ini memiliki banyak aliran di dalamnya, tetapi karena kajian ini bukan sebuah penelitian, mereka diasumsikan sebagai Salafi dengan alasan pada umumnya berpenampilan khas_-dengan gamis dan celana khasnya. Paling tidak, desa ini memiliki warga dengan tiga kelompok keagamaan besar yang tentu saja masih terdapat cabang-cabang di dalamnya yang belum dapat ditemukan (FGD Pengurus NU, 2020).

Untuk kepentingan pengabdian ini, tim sengaja tidak memasukkan unsur-unsur dan agama di luar Islam. Namun, dalam praktiknya, sudut pandang dari kelompok NU perlu dicari untuk memperkuat pentingnya pemahaman multikulturalisme bagi Nahdliyyin. Hal itu bukan sebagai cara untuk memberikan masukan terkait dengan persoalan multikulturalisme kepada warga NU, tetapi sebagai cara memahami pemahaman warga NU terhadap ajaran Nahdliyyah. Dengan memberikan materi konsep sederhana terkait dengan multikulturalisme dan mendengarkan umpan balik dari peserta pengabdian, sangat jelas ada relasi antara pemahaman multikulturalisme dengan pemahaman ajaran NU, yaitu Tawazun, Tawasuth, Tasamuh, dan I'tidal.

Pada pengabdian ini, di samping menggunakan perspektif "the other" atau "out group consciousness", sebagai cara melihat dan mempersepsikan orang lain dengan kesadaran orang lain, juga menggunakan perspektif "in group consciousness" atau "the self", yaitu membaca dari kelompok sendiri dengan sudut pandang dari diri sendiri (Abdullah, 1988; Dhont et al., 2009). Dengan demikian, mulitkulturalisme kemudian dapat dihubungkan dengan upaya pemahaman tentang hidup bersama, saling memahami, dan saling kerja sama, yang tidak hanya dipahami dengan hanya membaca orang dan kelompok lain dengan sudut pandang sendiri, tetapi juga bagaimana di antara anggota kelompok memahami satu sama lain dari sudut pandang lain. Lebih jelasnya, bagaimana NU tidak hanya melihat multikulturalisme sebagai cara membaca orang lain untuk bertoleran kepadanya, tetapi bagaimana NU melihat keragaman dalam dirinya sebagai cara membuktikan adanya sikap multikulturalistik dalam Jama'ah NU.

Dengan memperhatikan sudut pandang, baik sudut pandang "the other" maupun "The self", pelatihan ini memberikan pandangan dan pemahaman terkait dengan persoalan multikulturaslisme. Di sini tidak melakukan pemilahan dan pengelompokan secara ketat bagaimana Jama’ah NU mempersepsikan multikulturalisme sebagai strategi kebudayaan keagamaan di luar ajaran NU sendiri. NU sebagai organsasi keagamaan memiliki strategi kebudayaan berdasarkan ajaran Abl Al Sunnah Wa al-Jama'ah dengan menganut konsep Tasamuh (toleran), Tawasuth (moderat), I'tidal (adil), dan Tawazun (keseimbangan) (Akhyat, 1992). Keempat konsep tersebut merupakan strategi kebudayaan NU yang secara nasional menjadi panduan dalam melakukan gerakan kebudayaan 
(Akhyat, 1992). NU dengan empat konsep strategi kebudayaan tersebut menjadikan NU sebagai lembaga sosial keagamaan yang mengedepankan toleransi, moderat, menjunjung tinggi keadilan, dan melakukan sikap keseimbangan di antara pihak-pihak di luar NU.

Empat strategi kebudayaan tersebut tentu dalam praktiknya tidak sebagaimana konsep dan aturan formalnya. Perbedaan pandangan dan tafsir sangat mungkin terjadi, terutama dalam kasus-kasus di lingkungan sosial tertentu. Hal itu karena faktor pendidikan, status sosial, relasi dengan pesantren atau kyai sangat mungkin menjadi sebab perbedaan sudut pandang dalam menghadapi persoalan empat konsep di atas. Keikutsertaan pengajian, perkumpulan keorganisasian, serta acara lain yang terkait dengan acara keagamaan juga menjadi sebab yang biasanya menentukan cara pandang seseorang (Feillard,1999).

Dengan demikian, perbedaan pandangan terhadap empat konsep strategi kebudayaan NU tidak semua dimaknai sama oleh Jama'ah (aspek sosial komunitas) NU, begitu juga sering pada tingkat Jam'iyyah (kelembagaan) terjadi perbedaan sudut pandang. Oleh karena itu, pengabdian ini tidak hanya melihat perbedaan persepsi pada tingkat Jama'ah, tetapi juga Jam'iyyah. Pengabdian ini memberikan dasar pemahaman tentang multikulturalisme dan memberikan masukan terkait dengan tafsir dan praktik multikulturalisme sesuai sudut pandang ke-NU-an kemudian menjadi penting.

Pada kegiatan pengabdian ini diberikan pancingan diskusi dan "brainstorming" terkait dengan permasalahan internal NU dengan memberikan materi sejarah NU, perkembangan dan perubahan NU, serta NU dan multikulturalisme. Ketiga materi itu diberikan melalui diskusi kecil yang dilakukan bersama dengan pengurus syuriah dalam rapat pengurus.

Pada pertemuan tersebut, di samping mendengarkan persepsi dan pandangan pengurus terkait isu radikalisme, kesiapan jama'ah dalam menghadapi radikalisme serta penguatan jama'ah dan jam'iyyah juga menjadi materi pelatihan ini. Penjaringan pendapat dengan memberikan masukan berbagai persoalan ke-NU-an semakin memberikan pemahaman baru terkait dengan realitas sosial di kalangan NU. Hampir semua peserta belum memahami sejarah NU dan perubahan-perubahan sudut pandang NU terkait dengan multikulturalisme. Melalui cerita dan materi sejarah NU dan perubahan sudut pandang NU terkait dengan persoalan sosial, pengurus NU paling tidak mulai mengetahui implikasi konsep Abl al Sunnah wa Al Jama'ah dalam perubahan-perubahannya sejak tahun 1926.

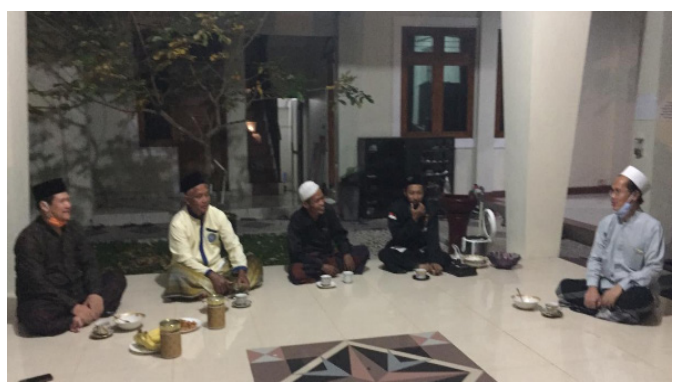

Gambar 1. FGD Multikulturalisme dengan Syuriah NU Desa Tamantirto. Sumber: Dok. Arif Akhyat.

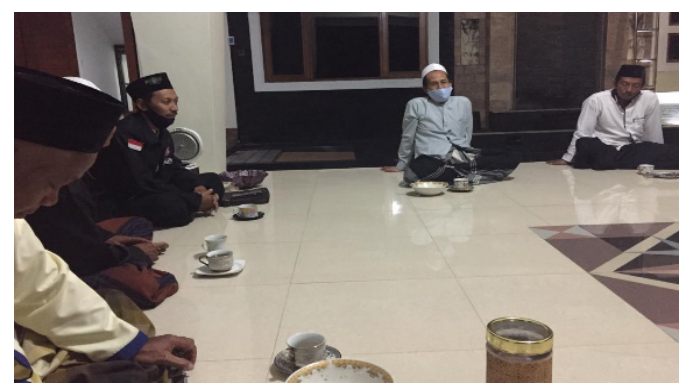

Gambar 2. Sosialisasi materi multikulturalisme dengan agenda dialog. Sumber: Dok. Arif Akhyat. 
Pada pertemuan banyak terungkap bagaimana pelaksanaan konsep Ahl al Sunnah wa al Jama'ah yang merupakan konsep dasar Tawasuth, Tawazun, Tasamuh, dan I'tidal menjadi metode teknis untuk melakanakan prinsip multikulturlisme. Keempat konsep strategi NU tersebut dijelaskan melalui metode ceramah secara daring serta pertemuan langsung dengan memanfaatkan rapat pengurus.

Pada pertemuan berikutnya juga dilakukan bersamaan dengan rapat pengurus. Namun, jumlah yang hadir tidak terlalu banyak karena bertepatan dengan rapat pemenangan pada Pilkada Bantul 2020. Pertemuan kali ini lebih banyak membicarakan persoalan demokrasi dan hak-hak politik. Pada pertemuan itu juga tidak ada yang memberikan padangan terkait dengan orientasi politik NU pada Pilkada Bantul 2020. Sesekali hanya menyinggung kenetralan NU dalam Pilkada Bantul 2020. Materi yang diberikan terkait dengan menjaga ukhuwwah atau persaudaraan ketika terjadi proses politik.

Pertemuan yang hampir tidak menggunakan protokal kesehatan karena ada suguhan yang diberikan saat rapat itu dilakukan dengan dipercepat. Dalam kesempatan itu, dapat diberikan materi terkait dengan demokrasi dan bagaimana demokrasi dipahami sebagai turunan konsep Ahlal Sunnah wa Al Jama'ah melalui pemahaman empat konsep strategi kebudayaan NU.

Pada pertemuan itu pula, cara pandang jama'ah terhadap konsep demokrasi mulai berubah dengan lebih memiliki wawasan kenegaraan dan kebangsaan. Demokrasi tidak hanya dipahami dalam konteks keislaman dan ke-NU-an, tetapi lebih dipahami sebagai konsep kenegaraan dan kebangsaan dengan tetap berpijak pada ke-NU-an. Pada
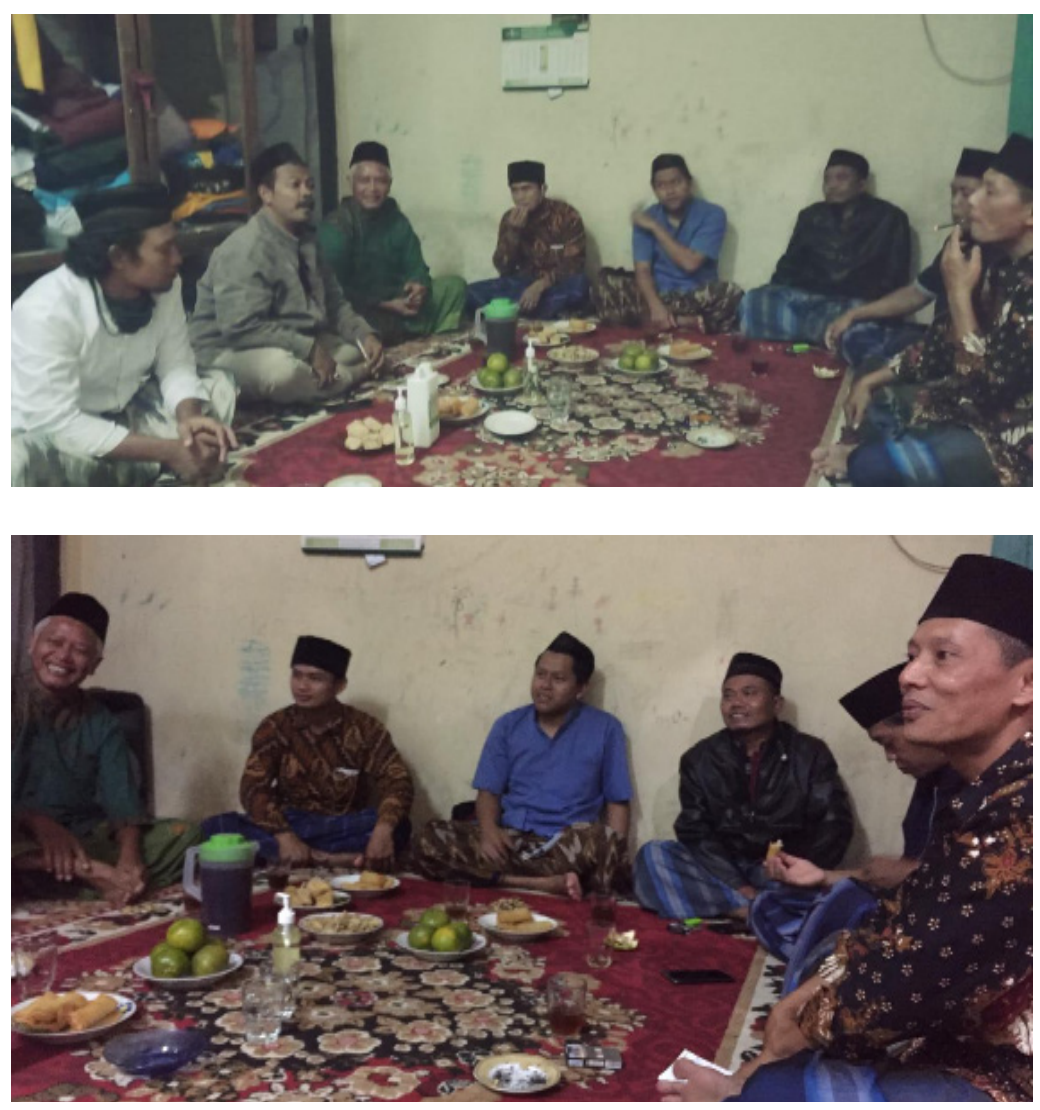

Gambar 3. FGD

Multikulturalisme bersamaan dengan Rapat Pengurus Tanfidziyah, Pengurus Ranting NU Desa Tamantirto. Sumber: Dok. Arif Akhyat.

Gambar 4. Rapat Pengurus Ranting NU Desa Tamantirto sekaligus FGD terkait demokrasi politik local menjelang Pilkada Bantul dan multikulturalisme. Sumber: Dok. Arif Akhyat. 
pertemuan ini juga banyak lontaran terkait dengan sebagian masyarakat yang dinilai belum melaksanakan demokrasi sebagaimana yang dipahami selama ini oleh NU. Bagi NU, pemahaman multikukturalisme seharusnya tetap berpegang pada pemahaman ke-NU-an dengan merujuk pandangan para Ulama (Akhyat, 1992; Hirokoshi, 1987).

Sebagai warga negara, NU bukan melebur dalam aturan tata negara semata, tetapi justru menjadi penerjemah pelaksanaan tata negara dan menjaga Negara Kesatuan Republik Indonesia dengan prinsip Ahl al Sunnah wa al Jama'ah dalam bingkai negara kesatuan. Secara sederhana, dapat dikatakan bahwa NU, paling tidak dari perspektif yang paling sederhana merupakan unsur negara dan patuh sepenuhnya kepada negara, karena NU merupakan organisasi yang ikut terlibat langsung mendirikan negara (Feillard, 1999; Hirokoshi, 1987). Tampaknya materi yang disampaikan pada pertemuan tersebut banyak mendapat tanggapan dan muncul kesadaran akan arti adanya perbedaan.

\section{Refleksi Capaian Program}

\section{NU dan Multikulturalisme: Kembali ke Khitthah.}

Pengabdian pada Masyarakat ini merupakan cara memberi materi dan memfasilitasi penyampaian materi multikulturalisme dari perspektif NU, khususnya dari Pengurus Ranting dan sebagian Jama’ah NU di Desa Tamantirto. Pada praktiknya, tidak banyak yang memahami arti dan makna multikulturalisme. Persoalan konsep multikulturalisme yang merupakan konsep asing dan memiliki kesan sebagai konsep yang tidak membumi menjadi persoalan dalam pengabdian ini. Secara prinsip, konsep multikulturalisme sebagaimana yang diberikan dalam beberapa pertemuan dan menjadi materi FGD serta interview daring maupun luring dan diskusi kecil pengurus yang bersamaan dengan rapat-rapat pengurus masih dipahami sebagai konsep baru. Ketika diadakan FGD melalui WhatsApp Group (WAG), prinsip multikulturalisme yang dipahami komunitas NU memiliki kesamaan dengan ajaran Ahl al Sunnah wa al Jama'ah yang oleh NU ditafsirkan lagi lebih pragmatis dengan konsp Tawazun, Tasaluh, Tawasuth, dan I'tidal (Barton, 2002; Fealy, 1998).

Kesamaan prinsip dalam pandangan warga NU tersebut kemudian bisa ditarik lebih jauh dengan apa yang pernah digariskan oleh Muktamar NU 1984, yaitu Kembali ke Khitthah 1926 (Feillard, 1999; Haidar, 1998). Pemahaman multikulturalisme yang muncul dapat dilihat sebagai cara Jama'ah NU ini menafsir Khitthah dengan mempertimbangkan berbagai aspek keragaman, baik pada tingkat sosial, budaya, politik, ekonomi, maupun juga sosial-keagamaan.

Multikulturalisme bagi NU adalah prinsip yang harus diselaraskan dengan nilainilai Ahl al Sunnah wa al Jama'ah dan kesepakatan ulama atau Ijma' sebagai dasar pelaksanaannya (Fattah, 2006). Melaksanakan Ijma' ulama sama dengan menjalankan prinsip multikulturalisme (Fealy, 1998). Oleh karena itu, perubahan telah terjadi dalam pengabdian masyarakat, dengan warga NU sebelumnya telah memahami apa yang dilakukan sebagai prinsip menjalankan perintah ulama dan ajaran Abl al Sunnah wa Al Jama'ah sehingga dengan pengabdian ini, mereka mulai menarik lebih luas bahwa prinsip Ahl al Sunnah wa Al Jama'ah merupakan ajaran yang sudah melingkupi apa yang menjadi konsep multikulturalisme serta memahami dan mengakui perbedaan berdasar pada konsep Tawazun, Tawasuth, Tasamuh, dan I'tidal. 


\section{Penutup}

Memperhatikan animo dan keingintahuan para Jamáah NU dalam persoalan sosial dengan mencoba memahami dari sudut pandang akademis sangatlah menarik untuk komunitas sebuah desa. Desa Tamantirto dengan segala keragaman dan perubahan yang cepat memberikan dampak langsung maupun tidak langsung bagi Nahdliyyin dalam menyikapi perubahan.

Di dalam diri Nahdliyin, perubahan-perubahan itu belum secepat yang terjadi di luar. Namun, persepsi, pemahaman, dan reaksi terhadap berbagai perubahan sosial diantisipasi dengan berbagai aksi. Mulai dari pengajian, bakti sosial, hingga kursus-kursus yang bersifat pragmatis dilakukan. Pemahaman tentang ke-NU-an dengan dasar Ahlal Sunna wa al Jama'ah dengan konsep empat dasar khas ke-NU-an, Tawasuth, Tawazun, Tasamuh, dan I'tidal tampak masih menjadi persoalan di kalangan Nahdliyyin. Ketika diberi masukan tentang konsep-konsep tersebut kemudian diterjemahkan dengan konsep multikulturalisme, semakin terbukalah pemahaman Nabdliyyin terkait multikulturalisme yang ternyata memililiki relevansi dan bahkan menjadi bagian dari ide-ide Ahl al Sunnah wa al Jama'ah.

\section{Daftar Pustaka}

\section{Laman Web}

(n.d.). Tamantirto. https://Tamantirto.bantulkab.go.id

\section{Laporan Penelitian}

Kementerian Pertanian Republik Indonesia. (2014). “Program Implementasi Tata Guna Lahan dan Pembukaan Lahan Pertanian Baru di Papua”. Jakarta: Kementan dan FTP-UGM.

UNDP dan PSPK UGM. (2004) "Access to Justice Based on Conflict Areas in 5 Provinces”. Yogyakarta: PSPK UGM.

\section{Artikel, Skripsi, dan Buku}

Abdullah, T. (Ed.). (2005). Sejarah Lokal di Indonesia. Yogyakarta: Gadjah Mada University Press.

Abdullah, T. dan Sharon Siddique (Eds.). (1988). Tradisi dan Kebangkitan Islam di Asia Tenggara. Jakarta: LP3ES.

Akhyat, A. (1992). "Islam dan Politik: Sikap Politik Nahdlatul Ulama pada Masa

Demokrasi Terpimpin”. Skripsi S-1 Ilmu Sejarah, Fakultas Sastra, UGM.

Barton, G. (2002). Biografi Gus Dur, Terjemahan. Yogyakarta: LKiS Pelangi Aksara.

Dhont, F. Fogg, dan Kevin W. (Eds.). (2009). Towards An Inclusive Democratic Indonesian

Society: Bridging the Gap between State Uniformity and Multicultural Identity Patterns.

Yogyakarta: Yale Indonesian Forum.

Fattah, M. A. (2006). Tradisi Orang-Orang NU. Yogyakarta: Pustaka Pesantren.

Fealy, G. (1998). Ijtihad Politik Ulama; Sejarah NU 1952-1967, Terjemahan. Yogyakarta:

LKiS Pelangi Aksara.Horikoshi, H. (1987). Kyai Dan perubahan sosial. Jakarta: P3M.

Klein, M. (Ed.). (1993). Breaking the Chains; Slavery, Bondage and Emancipation in

Modern Africa and Asia. Madison: University of Wisconsin Press. 
Haidar, M.A. (1998). Nahdlatul Ulama dan Islam di Indonesia, Pendekatan Fiqh dalam Politik. Jakarta: Gramedia.

Leur, J.C. (1995). Indonesian Trade and Society: Essays in Asian Social and Economic History. The Hague: van Hoeve.

Lombard, D. (1996). Nusa Jawa:Silang Budaya, 3 jilid. Jakarta: Gramedia.

Meilink-Roelofsz, M.A. (1969). Asian Trade and European Influences in the Indoensian Archipelago between 1500 and about 1630. The Hague: Nijhoff.

Reid, A. (2004). Sejarah Modern Awal Asia Tenggara. Jakarta:LP3ES. 